\title{
HISTORICAL PERSPECTIVES OF THE AMERICAN ASSOCIATION FOR THORACIC SURGERY
}

\section{NATHAN GREEN (1871-1955)}

$\mathrm{N}$ athan Green, the first secretary and seventh president of The American Association for Thoracic Surgery, a descendant of colonial American families on both sides, was born in Ceylon in 1871. His father, Samuel Fiske Green, was an 1845 graduate of the College of Physicians and Surgeons at Columbia University and, for a time, a physician in Ceylon under the American Board of Commissioners for Foreign Missions. Nathan graduated with honors from Yale in 1894. As an undergraduate he was a member of the College Choir, the University Glee Club, the Ivy Committee, Delta Kappa Epsilon, and Wolf's Head.

Green received his MA and MD degrees from Columbia, College of Physicians and Surgeons, in 1898 and served on the house staff of St. Luke's Hospital from July 1898 to July 1900. In October 1900 he opened an office for the practice of surgery in New York City. For a number of years after 1904, he also had a small office at Green Hill, Worcester, Massachusetts, where his father once practiced. He was assistant demonstrator of physiology at the College of Physicians and Surgeons until July 1902 and assistant surgeon at Roosevelt Hospital, 1903 to 1905 . He spent the summer of 1904 in European travel visiting the principal hospital clinics in London, Berlin, and Berne. He returned to an appointment at St. Luke's Hospital, with which his name is principally identified, and City Hospital. In 1907 and for a few years thereafter, he joined Henry Janeway at Memorial Hospital in Janeway's significant experimental work with esophageal carcinoma and esophagogastric anastomosis. This led eventually to an ingenious button that permitted anastomosis without freely opening either organ. Although the method was successful in the laboratory, it soon became apparent that direct suture was superior. The experience introduced Green to the laboratory, the problems of positive-pressure anesthesia, and the exciting possibilities of thoracic surgery and bronchoesophagoscopy.

Some measure of Green's surgical activity in the years preceding World War I is evident in the great number of his case reports in the transactions of the New York Surgical Society, to be found in the Annals of Surgery. Diversified in subject, they range from mesenteric thrombosis and resection of the rectum to gelatinous carcinoma of the bladder, gastrostomy in an infant, and depressed fracture of the skull. A majority of the reports, however, deal with thoracic problems, notably lung abscess and bronchiectasis, empyema, and postoperative drainage.

J Thorac Cardiovasc Surg 1997;113:1129

Copyright (c) 1997 by Mosby-Year Book, Inc.

$0022-5223 / 97 \$ 5.00+0 \quad \mathbf{1 2 / 5 4 / 7 5 5 0 3}$
He showed a special interest in the bronchoscopic removal of inhaled foreign bodies and esophagoscopy in the management of benign and malignant obstruction of the esophagus.

For the duration of World War I, Green "was retained at home on the request of the Dean of the College of Physicians and Surgeons for purposes of teaching sur-

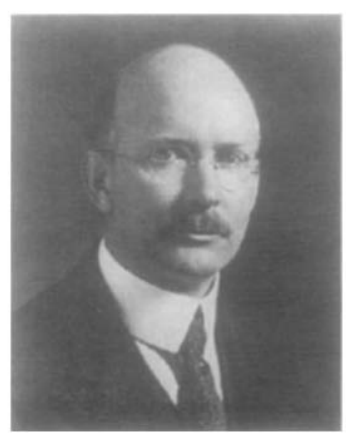
gery to medical students of the Senior class." He was available, therefore, in 1917 to play an active role as secretary-treasurer in the founding of the New York Association for Thoracic Surgery and its national offspring, the American Association the following year. Ethan Allen Butler, colorful and devoted chronicler and later president of the AATS, stated that more than anything else, "Nate Green's bookwork was responsible for the survival of the AATS." Any inspection of the correspondence in Dr. Butler's file substantiates Dr. Green's dedication to the cause.

Green's presidency of the AATS in 1925 reflected not only his devotion to the Association but, as his presidential address, "What May We Expect Today From Thoracic Surgery?" demonstrates, also his wide understanding of the specialty and a glimpse of the future. Tuberculosis takes center stage and, although Green had a general surgical familiarity with this disease, his interest was clearly in empyema and the surgical challenge of bronchiectasis. Speaking of tuberculosis, he made the important point that the isolation of patients with tuberculosis in sanitoria removed them from the surgical mainstream with the result of retarding surgical progress in this important field. Green actively supported collapse therapy, both artificial pneumothorax and staged thoracoplasty, as promoting healing through rest, and he strongly echoed Lilienthal's reminder that in the postoperative period the patient still had tuberculosis and needed time to heal. He had relatively little to say about carcinoma of the lung; esophageal cancer took precedence, although Green was not among the fortunate few who could claim an operative success in this disease.

Nathan Green carried on a solid practice of surgery and thoracic surgery at St. Luke's through the thirties, then retired to the leisurely life of New Canaan, Connecticut, for his later years. He died in 1955 at the age of 84 . In summing up his long career of service to thoracic surgery, one is left with the suggestion of an unsung hero.

J. Gordon Scannell, $M D$ 